\title{
PENERAPAN KONSEP KEPUASAN PELANGGAN PADA KEPUTUSAN PEMBELIAN SMARTPHONE DI ANDALAS MT. HARYONO BALIKPAPAN UNIVERSITAS BALIKPAPAN
}

\author{
Widyawati $^{1}$, Casmudi ${ }^{2}$, Ashari Sofyaun ${ }^{3}$ \\ Universitas Balikpapan ${ }^{1}$, Universitas Balikpapan ${ }^{2}$, Universitas Balikpapan ${ }^{3}$ \\ Po-el : Widya.wati@gmail.com ${ }^{1}$, casmudi@,uniba-bpn.ac.id ${ }^{2}$, ashari.sofyaun@uniba-bpn.ac.id ${ }^{3}$
}

\begin{abstract}
ABSTRAK
Konsep kepuasan pelanggan merupakan strategi dan upaya dalam setiap jenis usaha untuk bersaing secara kompetitif dimana mereka dituntut untuk menawarkan keunggulan dan kemudahan, menangkap dengan jeli serta berusaha untuk memahami dengan cepat dan tepat yang diinginkan dan dibutuhkan konsumen dan terus mengembangkan kualitas layanan yang terbaik secara konsisten. Dalam menjalankan usahanya, Andalas MT. Haryono Balikpapan berusaha untuk memberikan perhatian terhadap bukti fisik, kehandalan, daya tanggap, empati dan jaminan guna menciptakan kepuasan pelanggan. Tujuan dari penelitian ini untuk mengetahui bagaimana kualitas pelayanan dan kualitas produk terhadap keputusan pembelian smartphone di Andalas MT. Haryono Balikpapan. Penelitian ini melibatkan 1 Leader Store dan 5 pelanggan Andalas MT. Haryono Balikpapan yang di pilih pada saat observasi. Data ini di dapat menggunakan observasi, wawancara, dan studi dokumentasi serta di olah menggunakan teknik triangulasi sumber. Hasil penelitian di peroleh 3 indikator yang di rasakan belum puas oleh pelanggan yaitu penyediaan sarana, ketanggapan tim atau personil terhadap masalah yang di hadapi, penampilan dan kerapian tim atau personil.
\end{abstract}

\section{Kata Kunci : kepuasan pelanggan, keputusan pembelian}

\section{ABSTRACT}

The concept of customer satisfaction is a strategy and effort in each type of business to compete competitively where they are required to offer excellence and convenience, capture with observance and strive to understand quickly and precisely what consumers want and need and continue to develop the best quality service consistently. In running its business, Andalas MT. Haryono Balikpapan strives to give attention to physical evidence, reliability, responsiveness, empathy and assurance to create customer satisfaction. The purpose of this research is to find out how the quality of service and product quality on smartphone purchasing decisions in Andalas MT. Haryono Balikpapan. This study involved 1 Store Leader and 5 Andalas MT customers. Haryono Balikpapan selected at the time of observation. This data can use observation, interviews, and documentation studies as well as using source triangulation techniques. The results of the study obtained 3 indicators that were felt not satisfied by the customer, namely the provision of facilities, team or personnel responsiveness to the problems faced, the appearance and neatness of the team or personnel.

Keywords: customer satisfaction, purchasing decisions 


\section{PENDAHULUAN}

Mengingat perkembangan teknologi yang semakin dinamis, manusia dituntut dengan cepat dan tepat untuk bertindak agar tidak kalah bersaing, melihat kondisi seperti ini menyebabkan pebisnis semakin dituntut untuk mempunyai strategi yang tepat dalam memenuhi target volume penjualan. Hampir setiap produsen saat ini memproduksi smartphone yang berteknologi canggih dan mempunyai spesifikasi dan aplikasi yang super lengkap. Keputusan perusahaan melakukan tindakan perbaikan pelayanan yang sistematis merupakan payung yang menentukan dalam menindaklanjuti complain konsumen dari suatu kegagalan sehingga pada akhirnya mampu mengikat loyalitas konsumen (Ellu, 2005).

Menurut Ellu (2005), keputusan perusahaan melakukan tindakan perbaikan pelayanan yang sistematis merupakan payung yang menentukan dalam menindaklanjuti komplain konsumen dari suatu kegagalan sehingga pada akhirnya mampu mengikat loyalitas. Kepuasan pelanggan menjadi parameter penting sehingga bisnis dapat terus berkelanjutan. Disamping itu hal yang mendasari seseorang untuk melakukan keputusan pembelian akan dipengaruhi juga terhadap apa yang diinginkan. Semakin majunya perekonomian dan teknologi, berkembang pula strategi yang harus dijalankan perusahaan khususnya dibidang pemasaran.

Untuk itu perusahaan perlu memahami atau mempelajari kepuasaan pelanggan dalam hubungannya dengan pembelian yang dilakukan oleh konsumen tersebut. Keberhasilan perusahaan dalam pemasaran perlu didukung pemahaman yang baik mengenai kepuasan pelanggan, karena dengan memahami konsumen perusahaan dapat merancang apa saja yang diinginkan konsumen. Persaingan yang semakin ketat, dimana semakin banyak produsen yang terlibat dalam pemenuhan kebutuhan dan keinginan konsumen, menyebabkan setiap perusahaan harus menempatkan orientasi pada kepuasan pelanggan sebagai tujuan utama (Tjiptono 2008 :23).

Tujuan penelitian adalah untuk mengetahui kualitas pelayanan dan kualitas produk pada keputusan pembelian smartphone di Andalas MT. Haryono Balikpapan. Untuk memantau penerapan SOP di Andalas Celluler Store, Head Store memonitor langsung dilapangan dan laporan dari leader store atau cctv yang akan mengecek aktivitas pelayanan jasa yang diberikan oleh pegawai Andalas Celluler Store. Jumlah Pegawai Andalas Celluler Store khususnya di MT Haryono terbilang lebih banyak dibanding cabang lain yakni berjumlah 55 orang. Berdasarkan penelitian pengamat hal ini disebabkan oleh peningkatan jumlah konsumen. Oleh karena itu pemasaran dan kepuasan pelanggan dianggap sebagai salah satu unsur strategi yang harus diterapkan.

Hasil pengamatan peneliti diatas dapat diperkuat dengan penelitian yang dilakukan oleh Yayat Rukayat (2017) "Kualitas Pelayanan Publik Bidang Administrasi Kependudukan Di Kecamatan Pasir jambu "Hasil penelitian menunjukkan bahwa kualitas pelayanan publik bidang administrasi kependudukan di Kecamatan Pasirjambu dilihat dari aspek fasilitas fisik, kehandalan, daya tanggap, jaminan, empati yaitu bagian Pelayanan Umum di Kecamatan Pasirjambu belum memenuhi fasilitas pelayanan yang memadai untuk memberikan pelayanan kepada masyarakat. Masyarakat merasa puas dengan pelayanan yang di berikan Kecamatan Pasirjambu dalam aspek reliability mengenai 
kehandalan dalam menangani setiap keluhan masyarakat.

Pegawai dalam hal membantu masyarakat yang membutuhkan pelayanan khususnya masyarakat yang bingung dengan pelayanan sudah terlihat antara petugas dan pengunjung yang saling berkomunikasi. Keamanan di Kecamatan Pasirjambu sudah menunjukan upaya meningkatkan kualitas pelayanannya terkait memberikan rasa aman bagi masyarakat. Empati yang diberikan pihak Kecamatan Pasirjambu yaitu dengan memberikan kesan yang menyenangkan. Namun seiring berjalannya waktu Andalas Celluler Store mengalami penurunan jumlah konsumen sebesar $40 \%$, hal ini disebabkan kurangnya konsistensi pegawai dalam pelayanan jasa yang diberikan seperti sistem dalam penyampaian jasa yang kurang efektif. Disisi lain, Andalas Celluler Store harus menerapkan peningkatan pelayanan jasa yang diberikan. Sementara itu dalam mengevaluasi jasa, konsumen umumnya menggunakan beberapa faktor berikut :

a. Bukti langsung (tangibles), meliputi fasilitas fisik, perlengkapan, pegawai dan sarana komunikasi.

b. Keandalan (realibity), yakni kemampuan memberikan pelayanan yang dijanjikan dengan segera, akurat, dan memuaskan.

c. Daya tanggap (responsiveness), yaitu keinginan para staf dan karyawanuntuk membantu para pelanggan dan memberikan pelayanan dengan tanggap.

d. Jaminan (assurance), mencakup pengetahuan, kemampuan, kesopanan, dan sifat dapat dipercaya yang dimiliki para staf, bebas dari bahaya, risiko atau keraguan.

e. Empati, meliputi kemudahan dalam melakukan hubungan, komunikasi yang baik dan memahami kebutuhan para pelanggan.

\section{METODE PENELITIAN}

Penelitian ini merupakan penelitian kualitatif deskriftif adalah penelitian yang berlandaskan pada filsafat postpositivisme, digunakan untuk meneliti pada kondisi obyek yang alamiah (sebagai lawannya adalah eksperimen) dimana peneliti adalah sebagai instrumen kunci, teknik pengumpulan data dilakukan secara trangulasi (gabungan), analisis data bersifat induktif/kualitatif, dan hasil penelitian kualitatif lebih menekankan makna daripada generalisasi (Sugiyono,2016:9).

Triangulasi merupakan teknik pemeriksaan keabsahan data yang memanfaatkan sesuatu yang lain dalam membandingkan hasil wawancara terhadap objek penelitian. Pengecekan sejawat melalui diskusi, teknik ini dilakukan dengan cara mengekspos hasil sementara atau akhir yang diperoleh dalam bentuk diskusi analitik dengan rekan-rekan sejawat.

Adapun triangulasi adalah teknik pemeriksaan keabsahan data yang memanfaatkan sesuatu yang lain di luar data itu untuk keperluan pengecekan atau sebagai pembanding terhadap data itu. Triangulasi dengan sumber yang dilaksanakan pada penelitian ini yaitu membandingkan hasil wawancara dengan isi dokumen yang berkaitan. Triangulasi yang digunakan adalah Triangulasi Sumber untuk menguji kredibilitas data dilakukan dengan cara mengecek data yang telah diperoleh melalui beberapa sumber. Data yang telah dianalisis oleh peneliti sehingga menghaslkan suatu kesimpulan dan Triangulasi Teknik untuk menguji kredibilitas data dengan cara mengecek data kepada sumber yang sama 
dengan teknik yang berbeda. Misalnya data diperoleh dengan wawancara, lalu di cek dengan observasi, dan dokumentasi.

\section{HASIL DAN PEMBAHASAN}

Penyajian data hasil temuan penelitian ini di dasarkan pada urutan pertanyaan penelitian yang telah $\mathrm{d}$ ajukan di bab I mengenai : 1) Bagaimana kualitas pelayanan pada keputusan pembelian smartphone di Andalas MT. Haryono Balikpapan, 2) Bagaimana kualitas produk pada keputusan pembelian smartphone di Andalas MT. Haryono Balikpapan. Data yang sudah terhimpun kemudian di analisis secara kualitatif deskriftif. Berdasarkan kajian teori yang peneliti pilih sebagai landasan dasar penelitian ini. Peneliti hanya mengambil orang, subjek penelitian ini dengan maksud agar lebih mengetahui secara mendalam berkenaan dengan permasalahan yang diteliti.

Adapun karakteristik informan yang di pilih yaitu 1) Informan berusia 17-35 tahun, 2) Informan tidak dalam keterpaksaan dalam menjawab pertanyaan yang di ajukan, 3) Informan serius dalam menanggapi pertanyaan yang di berikan,4) Informan sedang melakukan transaksi. Penelitian ini merupakan studi pengambilan subjek penelitiannya berdasarkan pada masalah yang menjadi objek penelitian. Melalui perkembangan ini, peneliti mengambil sumber data dari 1 orang Leader store yaitu Bapak Idham dan 5 pelanggan Andalas MT.Haryono Balikpapan di antaranya Bapak Nanang, Bapak Amat, Bapak bayu, Ibu Fajeriah, dan Ibu Tika.

Setelah peneliti melakukan pengamatan observasi dan wawancara secara langsung, peneliti memperoleh data-data yang dibutuhkan dalam penelitian ini. Data tersebut kemudian dikumpulkan lalu disajikan dan disederhanakan berdasarkan indikatorindikator yang telah dikembangkan.

Tabel 1. Profil Informan

\begin{tabular}{|l|l|l|l|}
\hline No & Nama & Usia & Pekerjaan \\
\hline 1. & Pak Nanang & 25 tahun & Karyawan Swasta \\
\hline 2. & Pak Bayu & 24 tahun & Karyawan Swasta \\
\hline 3. & Pak Amat & 26 tahun & Karyawan Swasta \\
\hline 4. & Ibu Tika & 29 Tahun & Ibu rumah tangga \\
\hline 5. & Ibu fajeriah & 19 tahun & Pelajar \\
\hline 6. & Pak idham & 29 Tahun & Leader Store \\
\hline
\end{tabular}


Pada penelitian yang saya lakukan, konsumen banyak mengeluh karena terlalu lama menunggu pada saat proses jual beli berlangsung artinya dalam pelayanan bukti fisik perlu di perhatikan agar konsumen tidak menunggu terlalalu lama dan pada akhirnya kualitas layanan menjadi lebih baik lagi, dengan membiarkan konsumen menunggu terutama tanpa alasan yang jelas akan menimbulkan kesan negatif yang tidak seharusnya terjadi. Dalam memberikan pelayanan informasi Andalas MT.Haryono telah memberikan dengan baik namun pada saat penyampaian komentar ataupun saran dari konsumen, tim atau personil kurang cepat tanggap dalam mengatasinya, sehingga terjadinya kekecewaan dari konsumen itu sendiri. Hal ini terjadi karena kendala yang masih menggunakan proses manual dalam penyampaian saran konsumen.

Konsumen yang sedang melakukan pembelian atau pemilihan terhadap suatu produk mengharapkan keberadaannya diakui oleh penyedia jasa/penjual. Seorang informan mengatakan bahwa kurangnya pemberian informasi yang tepat membuat konsumen harus mencari sendiri kebenarannya. Jaminan segala sesuatu yang mempunyai nilai mudah untuk memberikan pelayanan yang diikat dengan janji sebagai jaminan untuk pelayanan berdasarkan perjanjian yang dibuat oleh konsumen dan penyedia jasa.

Tim atau personil Andalas MT. Haryono Balikpapan harus dapat menunjukkan sikap yang ramah, sopan dan akrab terhadap pergaulannya dengan masyarakat, mereka juga diwajibkan untuk jujur dalam setiap perkataan dan perilaku sehingga konsumen dapat memercayai mereka. Adanya persepsi yang kurang baik tentang prilaku karyawan dalam melayani konsumen. Sifat naluri untuk membantu yang diharapkan konsumen oleh setiap karyawan terhadap konsumen adalah keinginan konsumen.

Memahami serta memenuhi kepuasan konsumen merupakan salah satu tugas dalam memenuhi dan memahami keinginan konsumen diperlukan nilai-nilai kejujuran dari karyawan, kegiatan tersebut dapat berguna sebagai evaluasi yang dilakukan karyawan kepada konsumen sebagai pengalaman karyawan untuk dapat memberikan pelayanan yang terbaik yang setidaknya sama baiknya dengan apa yang diharapkan oleh masyarakat. Sehingga ada pendekatan tambahan dalam rangka untuk memberikan pembentukan kepuasan. produk handphone yang ada di Andalas MT.Haryono sangat mengikuti perkembangan zaman yang sesuai dengan kebutuhan konsumen memiliki garansi resminya serta memiliki ketahanan cukup kuat. 


\section{KESIMPULAN}

Kualitas layanan dan kualitas produk merupakan faktor penting di dalam usaha untuk meningkatkan kepuasan pelanggan, khususnya pada Andalas MT.Haryono Balikpapan. Dapat di simpulkan bahwa terdapat 3 indikator yang di anggap paling penting oleh pelanggan, tetapi pelanggan belum puas. Indikator tersebut adalah penyediaan sarana (bukti fisik), ketanggapan tim atau personil (daya tanggap) terhadap masalah yang di hadapi, pemberian informasi yang kurang konsisten (kehandalan). Serta di hasilkan 2 indikator yang di rasakan konsumen sudah puas dengan kualitas pelayanan Andalas MT.Haryono Balikpapan, di antaranya perhatian tim atau personil terhadap konsumen (empati), keramahan tim atau personil dalam memberikan pelayanan, jaminan akan kualitas produk dan lokasi yang strategis (jaminan)

\section{DAFTAR PUSTAKA}

\section{Arief,M. (2011). Kualitas}

Pelayanan Publik Di Bandara Internasional Sultan Hasanuddin Makassar. Jurnal Academica.Vol 3 No. 2

Ellu. (2005). Kualitas Pelayanan. (D. Aryani, \& F. Rosinta, Penyunt.)Pengaruh Kualitas Layanan Terhadap Kepuasan Pelanggan Dalam Membentuk
Loyalitas Pelanggan, Vol. 17 N0.2.

Hamdani, L. \&. (2006). Sistem Perbaikan Kualitas Pelayanan. (D. Aryani, \& F. Rosinta, Penyunt.) Pengaruh Kualitas Layanan Terhadap Kepuasan Pelanggan Dalam Membentuk Loyalitas Pelanggan, Vol. 17 No. 2.

Hidayatullah. (2006). Keputusan

Pembelian. (V. Yazia, Penyunt.) Pengaruh Kualitas Produk, Harga, Dan Iklan Terhadap Keputusan Pemelian Handphone Blackberry (Studi Kasus Blackberrt Center Veteran Padang), Vol. 2 No. 2.

Jacobis, R. (2013). Faktor-Faktor Kualitas PelayananPengaruhnya Terhadap Kepuasan Pasien Rawat Inap Peserta Jamkesmas Di BluRsup Prof.Dr. R.D. Kandou Manado. Jurnal EMBA. Vol 1No.4

Kotler. (2005). Pengertian Kualitas Produk. (D. Aryani, \& F. Rosinta, Penyunt.) Pengaruh Kualitas Layanan Terhadap Kepuasan Pelanggan Dalam Membentuk Loyalitas Pelanggan, Vol. 17 No.2 Tahun 2010.

Kotler. (2009). Tahap-tahap Dalam Proses Keputusan Pembelian. (V. Yazia, Penyunt.) Pengaruh Kualitas Produk, Harga, Dan 


Iklan Terhadap Keputusan

Pembelian Handphone Blackberry (Studi Kasus Blackberry Center Veteran Padang), Vol. 2 No. 2.

Novyarto, H. (2010). Pengaruh Prilaku Konsumen Mobile Internet Terhadap Keputusan Pembelian Paket Layanan CDMA. Jurnal Ekonomi, Vol. 2 No. 3 Tahun 2010.

Rukayat, Y. (2017). Kualitas Pelayanan Publik Bidang Administrasi Kependudukan Di Kecamatan Pasirjambu. Asministrasi Journal, No. 2 Tahun 2017.

Saidani, B., \& Arifin, S. (2012). Pengaruh Kualitas Produk Dan Kualitas Layanan Terhadap Kepuasan Konsumen Dan Minat Beli Pada Ranch Market. Riset Manajemen Sains Indonesia, Vol. 3 No.1 Tahun 2012.

Damiati, Masdarini, L., Suriani, M., Adnyawati, N. M., Marsiti, C. I., Widiartini, K., \& Angendarini, M. D. (2017). Perilaku Konsumen. Depok: PT. Rajagrafindo Persada dan Mixed. Cetakan 1 Pustka Pelajar. Yogyakarta.

Irawan, H. (2002). 10 Prinsip Kepuasan Pelanggan. Jakarta: PT. Elex Media Komputindo.

Irawan, H. (2003).Indonesian Customer Satification. Membedah Strategi Kepuasan Pelanggan

\section{Merek Pemenang ICSA.}

Jakarta: PT. Elex Media Komputindo.

Sugiyono. (2016). Metode Peneitian Kuantitatif, Kualitatif, dan $R \& D$. Bandung: Alfabeta. Susanto, A., \& Wijarnoko, H. (2004). Power Branding. Membangun Merek Unggul \& Organisasi Pendukung. Jakarta: PT. Nizam Publika.

Tjiptono, F. (2000). Pemasaran Jasa. Yogyakarta: CV. Andi Offset.

Tjiptono, F. (2008). Strategi Pemasaran Edisi III. Yogyakarta: CV. Andi Offset.

Umar, H. (2005). Riset Pemasaran \& Prilaku Konsumen. Jakarta: PT. Gramedia Pustaka Utama. 